International Journal of Environmental Research and

Public Health

ISSN 1660-4601

www.mdpi.com/journal/ijerph

Article

\title{
Association between Vitamin D Receptor Gene Polymorphisms with Childhood Temporal Lobe Epilepsy
}

\author{
Pei Jiang ${ }^{1,2, \dagger}$, Wen-Ye Zhu ${ }^{1, \dagger}$, Xin He ${ }^{1, \dagger}$, Mi-Mi Tang ${ }^{1}$, Rui-Li Dang ${ }^{1}$, Huan-De Li ${ }^{1, *}$, \\ Ying Xue ${ }^{1}$, Li-Hong Zhang ${ }^{1}$, Yan-Qin Wu ${ }^{1}$ and Ling-Juan Cao ${ }^{1}$ \\ 1 Institute of Clinical Pharmacy and Pharmacology, Second Xiangya Hospital, \\ Central South University, Changsha 410011, China; E-Mails: jpoet89@126.com (P.J.); \\ zhuwenyewawbmg@126.com (W.-Y.Z.); hexin526@126.com (X.H.); \\ tangmimi1989@126.com (M.-M.T.); ruilidang@gmail.com (R.-L.D.); \\ xueying091@126.com (Y.X.); zhanglihong0612@163.com (L.-H.Z.); \\ wuyanqin1992@163.com (Y.-Q.W.); caolingjuan@126.com (L.-J.C.) \\ 2 Department of Pharmacy, Jining First People's Hospital, Jining 272011, China \\ $\dagger$ These authors contributed equally to this work. \\ * Author to whom correspondence should be addressed; E-Mail: lihuande1953@126.com; \\ Tel./Fax: +86-731-8443-6720.
}

Academic Editor: Paul B. Tchounwou

Received: 27 August 2015 / Accepted: 28 October 2015 / Published: 30 October 2015

\begin{abstract}
Vitamin D (VD) is implicated in multiple aspects of human physiology and vitamin $\mathrm{D}$ receptor $(V D R)$ polymorphisms are associated with a variety of neuropsychiatric disorders. Although VD deficiency is highly prevalent in epilepsy patients and converging evidence indicates a role for VD in the development of epilepsy, no data is available on the possible relationship between epilepsy and genetic variations of $V D R$. In this study, 150 controls and 82 patients with temporal lobe epilepsy (TLE) were genotyped for five common VDR polymorphisms (Cdx-2, FokI, BsmI, ApaI and TaqI) by the polymerase chain reaction-ligase detection reaction method. Our results revealed that the frequency of FokI AC genotype was significantly higher in the control group than in the patients $(p=0.003, \mathrm{OR}=0.39,95 \% \mathrm{CI}=0.21-0.73)$, whereas the AA genotype of ApaI SNP was more frequent in patients than in controls $(p=0.018$, OR $=2.92,95 \% \mathrm{CI}=1.2-7.1)$. However, no statistically significant association was found between Cdx-2, BsmI and TaqI
\end{abstract}


polymorphisms and epilepsy. Additionally, in haplotype analysis, we found the haplotype GAT (BsmI/ApaI/TaqI) conferred significantly increased risk for developing TLE $(p=0.039, \mathrm{OR}=1.62,95 \% \mathrm{CI}=1.02-2.56)$. As far as we know, these results firstly underline the importance of $V D R$ polymorphisms for the genetic susceptibility to epilepsy.

Keywords: epilepsy; children; vitamin D receptor; polymorphisms

\section{Introduction}

Epilepsy is one of the most prevalent neurological disorders of childhood, affecting six out of every 1000 children, and it is about twice as common in children as in adults [1]. Temporal lobe epilepsy (TLE) is the most frequent form among epilepsies with focal seizure on set and displays resistance to antiepileptic drugs [2]. In approximately $20 \%-30 \%$ of cases, there is a clear extraneous acquired cause (e.g., head trauma, stroke), but in the remainder, genetic factors play a major role. Indeed, numerous association studies have shown the involvement of various genes in TLE and it is now believed that TLE is influenced by genetic variations as well as environmental factors [3,4].

Over the last decade, vitamin D (VD) is increasingly recognized as a neuroactive steroid modulating brain development and function in addition to its classical role in calcium-phosphate homeostasis and bone health. Multiple lines of evidence indicate that VD is implicated in numerous brain processes including regulating neurotrophic factors, neuroimmunomodulation and neurotransmission [5-7]. Poor VD status and genetic variations of vitamin D receptor $(V D R)$ are implicated in the pathogenesis of a number of neuropsychiatric disorders including Alzheimer's disease, depression and multiple sclerosis [8-10]. However, regarding epilepsy, while VD deficiency is frequently observed in children with epilepsy, most of the studies in this field focused on the association of VD deficiency with the reduced bone mineral density, but not with epilepsy itself. Recently, a pilot study found that correcting the deficient VD status can improve seizure control in epilepsy patients [11]. Additionally, animal studies also demonstrated that VD treatment can raise the electroconvulsive threshold in rats [12], and on the other hand, $V D R$ mutant mice displays increased susceptibility to chemically induced seizures [13]. Considering that certain genetic variations of $V D R$ may have regulatory effect on VD signaling and metabolism, it is tempting to hypothesize that the particular polymorphisms of $V D R$ could contribute to the development of epilepsy or subgroups of this condition, notably TLE. Therefore, we performed a genetic association analysis of five known VDR SNPs Cdx-2 (rs11568820), FokI (rs2228570), BsmI (rs1544410), ApaI (rs7975232) and TaqI (rs731236) in TLE patients and controls.

\section{Materials and Methods}

\subsection{Subjects}

A total of 82 unrelated Asian patients (39 females and 43 males; age range, 2-15 years; Han Chinese from Hunan Province) were included in this study. Patients with epilepsy were recruited at the outpatient clinic of the Second Xiangya Hospital. The patients were diagnosed and classified according to the guidelines of the International League Against Epilepsy. In each patient, the diagnosis of TLE 
was made on the basis of a range of clinical seizure semiology, EEG and MRI criteria that are considered to be reliable interictal indicators of TLE. The diagnosis of TLE was mainly based on typical temporal auras or ictal and interictal EEG discharges over the temporal lobes in the presence of focal spikes or sharp waves followed by slow waves. Clinical MRI examinations followed a protocol routinely used for patients with TLE, which briefly included high-resolution T1-weighted volume acquisition and T2-weighted and fluid-attenuated inversion recovery (FLAIR) sequences [14]. Brain MRI evaluation revealed evidence of hippocampal sclerosis in eight of the 82 patients. MRI did not detect any mass lesions such as tumors, cortical dysgenesis, vascular lesions, malformations or post-traumatic scars in any of the patients. None of them had mental retardation, psychiatric difficulties or early psychiatric manifestations. The mean age at seizure onset was $6.8 \pm 3.17$ years (range $0.25-12.72$ years) and the mean duration of epilepsy was $2.23 \pm 1.91$ years (range $0-7.70$ years). Six of the 82 patients had family histories of seizures or febrile convulsions in one or more first- to third-degree relatives. We also enrolled 150 healthy control subjects, 19 to 60 years of age, matched for sex and ethnicity, without a history of seizures, including febrile convulsions, related family histories or inherited central nerve system diseases. Written informed consent was signed by each participant or responsible adult before they participated in the study. The study was conducted in accordance with the Declaration of Helsinki, and the protocol was approved by the Ethics Committee of the Second Xiangya Hospital of Central South University (S209. 2012).

\subsection{DNA Isolation and Genotyping}

Genomic DNA was extracted from $1 \mathrm{~mL}$ of venous blood by the using SQ Blood DNA Kit II (D0714-250, OMEGA, Norcross, GA, USA) according to the manufacturer's instructions. The genotype of SNPs was analyzed using the polymerase chain reaction-ligase detection reaction (PCR-LDR) method. The primers for both PCR and LDR reactions were all designed by the Primer3 online software v.0.4.0 (http://frodo.wi.mit.edu/) and are shown in Table 1. These PCR products and the LDR probes were then subjected to a multiplex LDR reaction, with a DNA sequencer used to detect the products. To test the validity of this procedure, approximately $10 \%$ of the samples were randomly selected and retested using the same procedure. The products generated in the retested samples were consistent with those obtained in the original sample.

Table 1. Primers of target genes used in the PCR.

\begin{tabular}{|c|c|c|c|}
\hline SNP & Ancestor Allele & Primer Sequence & Product Size \\
\hline $\begin{array}{c}\mathrm{Cdx}-2 \\
\text { (rs } 11568820)\end{array}$ & A & $\begin{array}{l}\text { 5'-CATCTTTTGTATCAGGAAC-3' (forward) } \\
\text { 5'-AACTGCAACCCATAATAAG-3' (reverse) }\end{array}$ & $103 \mathrm{bp}$ \\
\hline $\begin{array}{c}\text { FokI } \\
(\mathrm{rs} 2228570)\end{array}$ & A & $\begin{array}{l}\text { 5'-TGGCCTGCTTGCTGTTCTTA-3' (forward) } \\
\text { 5'-AAGTCTCCAGGGTCAGGCA-3' (reverse) }\end{array}$ & 92 bp \\
\hline $\begin{array}{c}\text { BsmI } \\
(\operatorname{rs} 1544410)\end{array}$ & G & $\begin{array}{l}\text { 5'-AGCCCAGTTCACGCAAGAG-3' (forward) } \\
\text { 5'-TAGATAAGCAGGGTTCCTGG-3' (reverse) }\end{array}$ & $100 \mathrm{bp}$ \\
\hline $\begin{array}{c}\text { ApaI } \\
\text { (rs7975232) }\end{array}$ & $\mathrm{C}$ & $\begin{array}{l}\text { 5'-TTGAGTGTCTGTGTGGGTGG-3' (forward) } \\
\text { 5'-TTAGAGAAGAAGGCACAGGAG-3' (reverse) }\end{array}$ & $99 \mathrm{bp}$ \\
\hline $\begin{array}{c}\text { TaqI } \\
\text { (rs731236) }\end{array}$ & $\mathrm{T}$ & $\begin{array}{l}\text { 5'-TTCTCTATCCCCGTGCCCA-3' (forward) } \\
\text { 5'-TTGGACAGGCGGTCCTGGAT-3' (reverse) }\end{array}$ & 84 bp \\
\hline
\end{tabular}




\subsection{Statistical Analysis}

The Hardy-Weinberg equilibrium was assessed for every SNP in the controls by Chi-square test ( $\chi 2$ test). Haplotype analysis was performed using the online SHEsis software at http://analysis.biox.cn (Shanghai, China). Odds ratio (OR) and the 95\% confidence interval (CI) were calculated using the unconditional logistic regression analysis to evaluate the association between each SNP and the risk of TLE with adjustment for age and gender. All the results were analyzed using the SPSS version 13.0 software (SPSS Inc., Chicago, IL, USA). The two-sided $p$ values of less than 0.05 were considered statistically significant.

\section{Results}

\subsection{Genotype and Allele Frequencies of the VDR Polymorphisms}

The genotype and allele frequencies of all five $V D R$ SNPs in the two groups are shown in Table 2. Each SNP was examined with Hardy-Weinberg equilibrium among controls and no significant difference was observed. The frequency of FokI AC genotype was found to be significantly higher in the control group than in the patients $(p=0.003, \mathrm{OR}=0.39,95 \% \mathrm{CI}=0.21-0.73)$, indicating a potential association with neuroprotection.

Table 2. Genotype and allele distribution of the VDR polymorphisms among cases and controls and the association with the risk of epilepsy.

\begin{tabular}{cccccc}
\hline SNP & Genotype/Allele & Cases $\boldsymbol{n}(\%)$ & Controls $\boldsymbol{n}(\%)$ & OR (95\% CI) & $\boldsymbol{p}$ Value \\
\hline Cdx-2 & GG & $28(34.1)$ & $44(29.3)$ & & $(1.095-3.281)$ \\
(rs11568820) & AG & $39(47.6)$ & $73(48.7)$ & $0.84(0.46-1.56)$ & 0.58 \\
& AA & $15(18.3)$ & $33(22.0)$ & $0.71(0.33-1.55)$ & 0.39 \\
& G & $95(57.9)$ & $161(53.7)$ & & \\
FokI & A & $69(47.1)$ & $139(46.3)$ & $1.19(0.81-1.75)$ & 0.38 \\
(rs2228570) & CC & $32(39.0)$ & $33(22.0)$ & & \\
& AC & $34(41.5)$ & $86(57.3)$ & $0.39(0.21-0.73)$ & 0.003 \\
& AA & $16(19.5)$ & $31(20.1)$ & $0.52(0.24-1.12)$ & 0.095 \\
BsmI & A & $66(40.2)$ & $148(49.3)$ & & \\
(rs1544410) & C & $98(59.8)$ & $152(50.7)$ & $1.446(0.98-2.22)$ & 0.06 \\
& GG & $72(87.8)$ & $133(88.7)$ & & \\
& AG & $7(8.5)$ & $16(10.7)$ & $0.81(0.32-2.10)$ & 0.66 \\
& AA & $3(3.7)$ & $1(0.7)$ & $5.54(0.57-54.25)$ & 0.14 \\
ApaI & G & $151(92.1)$ & $282(94.0)$ & & \\
(rs7975232) & A & $13(7.9)$ & $18(6.0)$ & $1.35(0.64-2.83)$ & 0.43 \\
& CC & $41(50.0)$ & $79(52.7)$ & & \\
& AC & $26(31.7)$ & $61(40.7)$ & $0.82(0.15-1.49)$ & 0.52 \\
& AA & $15(18.3)$ & $10(6.7)$ & $2.92(1.20-7.14)$ & 0.018 \\
& C & $108(65.9)$ & $219(73.0)$ & & \\
\hline
\end{tabular}


Table 2. Cont.

\begin{tabular}{cccccc}
\hline SNP & Genotype/Allele & Cases $\boldsymbol{n}(\%)$ & Controls $\boldsymbol{n}(\%)$ & OR (95\% CI) & $\boldsymbol{p}$ Value \\
\hline TaqI & TT & $72(87.8)$ & $127(84.7)$ & & \\
$($ rs731236) & CT & $6(7.3)$ & $21(14.0)$ & $0.51(0.19-0.31)$ & 0.16 \\
& CC & $4(4.9)$ & $2(1.3)$ & $3.53(0.63-19.74)$ & 0.15 \\
& T & $150(91.5)$ & $275(91.7)$ & & \\
& C & $14(8.5)$ & $25(8.3)$ & $1.03(0.52-2.03)$ & 0.94 \\
\hline
\end{tabular}

Abbreviations: CI, confidence interval; OR, odds ratio.

Meanwhile, the AA genotype of ApaI SNP was more frequent in cases than in controls suggesting an association with increased susceptibility to TLE $(p=0.018, \mathrm{OR}=2.92,95 \% \mathrm{CI}=1.2-7.1)$. However, there was no statistically significant difference between patients and controls for the genotype and allele distributions of Cdx-2, BsmI and TaqI polymorphisms.

\subsection{Haplotype Analysis}

In accordance with previous findings [15], BsmI, ApaI and TaqI were found to be in strong linkage disequilibrium (BsmI/ApaI: D' $=0.797, \mathrm{r} 2=0.279$; BsmI/TaqI: D' = 0.676, r2 = 0.356; ApaI/TaqI: $\left.\mathrm{D}^{\prime}=0.835, \mathrm{r} 2=0.223\right)$. Haplotype frequencies are shown in Table 3 . The haplotype analysis revealed that haplotype GAT significantly increased the risk of TLE in childhood $(p=0.039, \mathrm{OR}=1.62$, $95 \% \mathrm{CI}=1.02-2.56)$. This effect was not detected in any other common haplotypes.

Table 3. Haplotype frequencies for $V D R$ polymorphisms in cases and controls.

\begin{tabular}{ccccc}
\hline $\begin{array}{c}\text { Haplotype } \\
\text { (BsmI/ApaI/TaqI) }\end{array}$ & $\begin{array}{c}\text { Cases } \\
\mathbf{2 n}=\mathbf{1 6 4}(\mathbf{\%})\end{array}$ & $\begin{array}{c}\text { Controls } \\
\mathbf{n}=\mathbf{3 0 0}(\boldsymbol{\%})\end{array}$ & OR (95\% CI) & $\boldsymbol{p}$ Value \\
\hline AAC & $7.98(4.9)$ & $12.78(4.3)$ & $1.19(0.48-2.94)$ & 0.71 \\
GAC & $2.02(1.2)$ & $12.22(4.1)$ & $0.30(0.07-1.36)$ & 0.10 \\
GAT & $41.98(25.6)$ & $54.65(18.2)$ & $1.62(1.02-2.56)$ & 0.039 \\
GCT & $104.00(63.4)$ & $215.13(71.7)$ & $0.74(0.49-1.13)$ & 0.16 \\
\hline
\end{tabular}

Abbreviations: CI, confidence interval; OR, odds ratio. Haplotypes were omitted if the estimated haplotype frequency was $<3 \%$.

\section{Discussion}

This work firstly showed the potential association of $V D R$ polymorphisms and $V D R$ haplotypes with the susceptibility to TLE among Chinese children. Genetic variations of $V D R$ are known to have a significant effect on VD signaling and the five mostly studied SNPs (Cdx-2, FokI, BsmI, ApaI and TaqI) have been linked to an increased risk of a variety of diseases. FokI polymorphism is located inside the translation initiation codon of $V D R$ and if this SNP contains $C$ allele, an alternative start side is used, resulting in a three amino acid shorted protein, which may lead to altered VDR function [16]. $\mathrm{Cdx}-2$ is an A-G transition in the intestine-specific binding site of transcription factor Cdx-2, located in the 5' promoter region of $V D R$. An allele of this SNP is associated with lower VDR promoter activity [17]. The three SNPs located near the 3' un-translated region (3'UTR) (BsmI, ApaI and TaqI), albeit not functional, are linked with a poly (A) microsatellite repeat in the $3^{\prime} \mathrm{UTR}$ that 
could influence the $V D R$ mRNA stability [18]. While previous data have linked these SNPs with multiple neurological disorders, the evidence concerning the relationship between $V D R$ polymorphisms and epilepsy remains blank.

Deficient VD status is frequently observed in patients with epilepsy [19]. However, due to the increased rates of bone fractures and abnormalities in epilepsy patients, the influence of antiepileptic drugs (AEDs) on VD levels and bone metabolism is the mostly studied aspect of epilepsy and VD [20]. AEDs can induce the VD catabolizing cytochrome P450 enzymes and accelerate the conversion of VD into its inactive metabolites [21] and the $V D R$ polymorphisms are associated with the drug-induced reduction in bone mineral density [22]. Interestingly, recent studies indicate that even before AED treatment, VD deficiency is highly prevalent in children with epilepsy [23] and the circulating VD concentrations continue to decrease following months of antiepileptic medication [24]. Considering the varied neurological activity of VD, there exists a possibility that VD deficiency or suboptimal VD signaling may increase the susceptibility to epilepsy. The evidence from clinical VD supplementation studies and animal researches also support the antiepileptic action of VD. Furthermore, the association between VDR polymorphisms with TLE found in this study further adds weight to the theory that VD signaling might be involved in the development of epilepsy.

Several lines of evidence indicate that the genetic variations of FokI can affect circulating VD status and are associated with many neuropsychiatric diseases. The FokI A allele was found to be associated with neuroprotection and $\mathrm{C}$ allele may increase the risk of several neurological disorders, including Parkinson's disease, Alzheimer's disease and multiple sclerosis [25-28]. Consistent with previous findings, we also found modestly but non-significantly higher frequency of $\mathrm{C}$ allele $(p=0.06)$ in patients with epilepsy. Likewise, several studies also showed the association between the SNPs in the 3 'end of $V D R$ gene (BsmI, ApaI and TaqI) and brain dysfunctions [29,30]. However, in addition to that the AA genotype of ApaI slightly increased the risk of TLE ( $p=0.018$ ), we did not observe statistically significant differences in the genotype or allele frequencies of BsmI and TaqI between patients and controls, which can be explained by either a lack of effect of these SNPs on TLE or be due to a limited number of cases. Notably, single marker association analysis is sometimes not sufficient in complex diseases, whereas the haplotype-based linkage disequilibrium mapping has become a powerful tool for genetic association studies. In the present study, strong linkage disequilibrium was observed among the three SNPs in the 3'end of $V D R$ gene, which confirms previous findings [15], and our data suggest that the haplotype GAT is likely to be a disease-risk haplotype, which may affect RNA splicing, processing and editing. In accordance with our findings, the frequency of this haplotype was also found higher in patients with asthma, cardiovascular disease and obesity [15,30-33]. Thus, it is becoming increasingly necessary for future studies to examine the effect of these SNPs or haplotypes on the interaction and activity characteristics of $V D R$ protein.

Multiple actions of VD are likely to underlie its anticonvulsant effect. Altered $\gamma$-aminobutyric acid (GABA) status has been found in the brain tissues of rodents fed with a VD deficient diet [34] and we recently found that chronic administration of 1,25-dihydroxyvitamin $\mathrm{D}\left[1,25(\mathrm{OH})_{2} \mathrm{D}\right]$, the active form of VD, can elevate GABA concentrations and promote glutamate decarboxylase (GAD) 67 and GAD65 mRNA expression in rat brain [6], whereas attenuated GABAergic neurotransmission is highly relevant to the progression of epilepsy [35]. Additionally, VD is also implicated as a neuro-immunomodulator and can suppress the proconvulsant inflammatory cytokines [36]. 
Furthermore, there is evidence that VD can protect the neural cells from excessive unbuffered calcium and reactive oxygen species, the key factors of glutamate excitotoxicity [37].

However, it should be noted that the interpretation of our data is complicated by the puzzling finding that while heterozygous FokI AC genotype seems to increase the resistance to TLE, the two homozygous genotypes had no effect on the susceptibility. These results can be explained by that the relatively small sample size in each genotype has insufficient statistically power to detect a slight effect, which is a major limitation of the present study. Our study is also limited by the failure of controlling for the potential confounding factors, such as sunshine exposure and the intake of VD and calcium. Additionally, we also failed to analyze the serum VD status and functional consequence of these genetic variations. Considering that the interactions between various genes and (or) environmental factors play a role in the actions of $V D R$, the association between $V D R$ polymorphisms and TLE is likely to be confounded by the various potential gene-gene and (or) gene-environmental interactions. Thus, future studies are needed to further determine the effects of these SNPs on circulating VD status or the expression of the key components of VD signaling in the brain tissues or the peripheral blood mononuclear cells of seizure patients, which would lend more support to the relationship between VD and epilepsy.

\section{Conclusions}

In conclusion, we found a significant association between $V D R$ genetic variations and the risk of TLE in a Chinese Han population. Our data provide new evidence for the involvement VD in the development of epilepsy, which should promote replication studies in ethnically disparate populations in cohort study samples and with variants covering the whole gene.

\section{Acknowledgments}

This work was supported by Hunan Provincial Innovation Foundation for Postgraduate (No. CX2013B099) and National Natural Science Foundation of China (No. 81101001).

\section{Author Contributions}

Pei Jiang and Huan-De Li designed the study and wrote the protocol. Wen-Ye Zhu, Xin He and Yan-Qin Wu performed the genotyping and statistical analysis. Mi-Mi Tang, Ying Xue, Rui-Li Dang, Li-Hong Zhang and Ling-Juan Cao contributed the collection of materials. Pei Jiang and Wen-Ye Zhu wrote the manuscript. All authors contributed to have approved the final manuscript.

\section{Conflicts of Interest}

The authors declare no conflict of interest.

\section{References}

1. Geerts, A.; Arts, W.F.; Stroink, H.; Peeters, E.; Brouwer, O.; Peters, B.; Laan, L.; van Donselaar, C. Course and outcome of childhood epilepsy: A 15-year follow-up of the Dutch study of epilepsy in childhood. Epilepsia 2010, 51, 1189-1197. 
2. Wilson, S.J.; Micallef, S.; Henderson, A.; Rayner, G.; Wrennall, J.A.; Spooner, C.; Harvey, A.S. Developmental outcomes of childhood-onset temporal lobe epilepsy: A community-based study. Epilepsia 2012, 53, 1587-1596.

3. Fanciulli, M.; Pasini, E.; Malacrida, S.; Striano, P.; Striano, S.; Michelucci, R.; Ottman, R.; Nobile, C. Copy number variations and susceptibility to lateral temporal epilepsy: A study of 21 pedigrees. Epilepsia 2014, 55, 1651-1658.

4. Balan, S.; Sathyan, S.; Radha, S.K.; Joseph, V.; Radhakrishnan, K.; Banerjee, M. Gabrg2, rs211037 is associated with epilepsy susceptibility, but not with antiepileptic drug resistance and febrile seizures. Pharmacogenet. Genom. 2013, 23, 605-610.

5. Groves, N.J.; McGrath, J.J.; Burne, T.H. Vitamin D as a neurosteroid affecting the developing and adult brain. Annu. Rev. Nutr. 2014, 34, 117-141.

6. Jiang, P.; Zhang, L.H.; Cai, H.L.; Li, H.D.; Liu, Y.P.; Tang, M.M.; Dang, R.L.; Zhu, W.Y.; Xue, Y.; He, X. Neurochemical effects of chronic administration of calcitriol in rats. Nutrients 2014, 6, 6048-6059.

7. Sanchez, B.; Relova, J.L.; Gallego, R.; Ben-Batalla, I.; Perez-Fernandez, R. 1,25dihydroxyvitamin D3 administration to 6-hydroxydopamine-lesioned rats increases glial cell linederived neurotrophic factor and partially restores tyrosine hydroxylase expression in substantia nigra and striatum. J. Neurosci. Res. 2009, 87, 723-732.

8. Eyles, D.W.; Burne, T.H.; McGrath, J.J. Vitamin D, effects on brain development, adult brain function and the links between low levels of vitamin D and neuropsychiatric disease. Front. Neuroendocrinol. 2013, 34, 47-64.

9. Shen, L.; Ji, H.F. Vitamin D deficiency is associated with increased risk of Alzheimer's disease and dementia: Evidence from meta-analysis. Nutr. J. 2015, 14, doi:10.1186/s12937-015-0063-7.

10. Spedding, S. Vitamin D and depression: A systematic review and meta-analysis comparing studies with and without biological flaws. Nutrients 2014, 6, 1501-1518.

11. Hollo, A.; Clemens, Z.; Kamondi, A.; Lakatos, P.; Szucs, A. Correction of vitamin D deficiency improves seizure control in epilepsy: A pilot study. Epilepsy Behav. 2012, 24, 131-133.

12. Kalueff, A.V.; Minasyan, A.; Tuohimaa, P. Anticonvulsant effects of 1,25-dihydroxyvitamin D in chemically induced seizures in mice. Brain Res. Bull. 2005, 67, 156-160.

13. Kalueff, A.V.; Minasyan, A.; Keisala, T.; Kuuslahti, M.; Miettinen, S.; Tuohimaa, P. Increased severity of chemically induced seizures in mice with partially deleted vitamin D receptor gene. Neurosci. Lett. 2006, 394, 69-73.

14. Labate, A.; Ventura, P.; Gambardella, A.; le Piane, E.; Colosimo, E.; Leggio, U.; Ambrosio, R.; Condino, F.; Messina, D.; Lanza, P.; et al. Mri evidence of mesial temporal sclerosis in sporadic "benign” temporal lobe epilepsy. Neurology 2006, 66, 562-565.

15. Maalmi, H.; Sassi, F.H.; Berraies, A.; Ammar, J.; Hamzaoui, K.; Hamzaoui, A. Association of vitamin $\mathrm{D}$ receptor gene polymorphisms with susceptibility to asthma in Tunisian children: A case control study. Hum. Immunol. 2013, 74, 234-240.

16. O’Neill, V.; Asani, F.F.; Jeffery, T.J.; Saccone, D.S.; Bornman, L. Vitamin D receptor gene expression and function in a South African population: Ethnicity, vitamin D and FokI. PLoS ONE 2013, 8, doi:10.1371/journal.pone.0067663. 
17. Wang, L.; Hara, K.; van Baaren, J.M.; Price, J.C.; Beecham, G.W.; Gallins, P.J.; Whitehead, P.L.; Wang, G.; Lu, C.; Slifer, M.A.; et al. Vitamin D receptor and Alzheimer's disease: A genetic and functional study. Neurobiol. Aging 2012, 33, doi:10.1016/j.neurobiolaging.2011.12.038.

18. Uitterlinden, A.G.; Fang, Y.; van Meurs, J.B.; Pols, H.A.; van Leeuwen, J.P. Genetics and biology of vitamin D receptor polymorphisms. Gene 2004, 338, 143-156.

19. Hollo, A.; Clemens, Z.; Lakatos, P. Epilepsy and vitamin D. Int. J. Neurosci. 2014, 124, 387-393.

20. Cebeci, A.N.; Ekici, B. Epilepsy treatment by sacrificing vitamin D. Expert Rev. Neurother. 2014, 14, 481-491.

21. Pascussi, J.M.; Robert, A.; Nguyen, M.; Walrant-Debray, O.; Garabedian, M.; Martin, P.; Pineau, T.; Saric, J.; Navarro, F.; Maurel, P.; et al. Possible involvement of pregnane X receptor-enhanced cyp24 expression in drug-induced osteomalacia. J. Clin. Investig. 2005, 115, 177-186.

22. Phabphal, K.; Limapichart, K.; Sathirapanya, P.; Setthawatcharawanich, S.; Witeerungrot, N.; Geater, A.; Thammakumpee, N.; Leelawattana, R. The association between bsmi polymorphism and bone mineral density in young patients with epilepsy who are taking phenytoin. Epilepsia 2013, 54, 249-255.

23. Sonmez, F.M.; Donmez, A.; Namuslu, M.; Canbal, M.; Orun, E. Vitamin D deficiency in children with newly diagnosed idiopathic epilepsy. J. Child Neurol. 2015, 30, 1428-1432.

24. Lee, Y.J.; Park, K.M.; Kim, Y.M.; Yeon, G.M.; Nam, S.O. Longitudinal change of vitamin D status in children with epilepsy on antiepileptic drugs: Prevalence and risk factors. Pediatr. Neurol. 2015, 52, 153-159.

25. Emerah, A.A.; El-Shal, A.S. Role of vitamin D receptor gene polymorphisms and serum 25-hydroxyvitamin d level in Egyptian female patients with systemic lupus erythematosus. Mol. Biol. Rep. 2013, 40, 6151-6162.

26. Lee, Y.H.; Kim, J.H.; Song, G.G. Vitamin D receptor polymorphisms and susceptibility to Parkinson's disease and Alzheimer's disease: A meta-analysis. Neurol. Sci. 2014, 35, 1947-1953.

27. Gezen-Ak, D.; Dursun, E.; Bilgic, B.; Hanagasi, H.; Ertan, T.; Gurvit, H.; Emre, M.; Eker, E.; Ulutin, T.; Uysal, O.; et al. Vitamin D receptor gene haplotype is associated with late-onset Alzheimer's disease. Tohoku J. Exp. Med. 2012, 228, 189-196.

28. Cierny, D.; Michalik, J.; Kurca, E.; Dobrota, D.; Lehotsky, J. Foki vitamin D receptor gene polymorphism in association with multiple sclerosis risk and disability progression in Slovaks. Neurol. Res. 2015, 37, 301-308.

29. Kuningas, M.; Mooijaart, S.P.; Jolles, J.; Slagboom, P.E.; Westendorp, R.G.; van Heemst, D. $\mathrm{Vdr}$ gene variants associate with cognitive function and depressive symptoms in old age. Neurobiol. Aging 2009, 30, 466-473.

30. Petersen, M.S.; Bech, S.; Christiansen, D.H.; Schmedes, A.V.; Halling, J. The role of vitamin D levels and vitamin D receptor polymorphism on Parkinson's disease in the Faroe Islands. Neurosci. Lett. 2014, 561, 74-79.

31. Bodoki, L.; Chen, J.Q.; Zeher, M.; Nagy-Vincze, M.; Griger, Z.; Zilahi, E.; Danko, K. Vitamin D receptor gene polymorphisms and haplotypes in Hungarian patients with idiopathic inflammatory myopathy. Biomed. Res. Int. 2015, 2015, doi:10.1155/2015/809895. 
32. Dorsch, M.P.; Nemerovski, C.W.; Ellingrod, V.L.; Cowger, J.A.; Dyke, D.B.; Koelling, T.M.; Wu, A.H.; Aaronson, K.D.; Simpson, R.U.; Bleske, B.E. Vitamin D receptor genetics on extracellular matrix biomarkers and hemodynamics in systolic heart failure. J. Cardiovasc. Pharmacol. Ther. 2014, 19, 439-445.

33. Al-Daghri, N.M.; Guerini, F.R.; Al-Attas, O.S.; Alokail, M.S.; Alkharfy, K.M.; Draz, H.M.; Agliardi, C.; Costa, A.S.; Saulle, I.; Mohammed, A.K.; et al. Vitamin D receptor gene polymorphisms are associated with obesity and inflammosome activity. PLoS ONE 2014, 9, doi:10.1371/journal.pone.0102141.

34. Groves, N.J.; Kesby, J.P.; Eyles, D.W.; McGrath, J.J.; Mackay-Sim, A.; Burne, T.H. Adult vitamin D deficiency leads to behavioural and brain neurochemical alterations in $\mathrm{c} 57 \mathrm{bl} / 6 \mathrm{j}$ and balb/c mice. Behav. Brain Res. 2013, 241, 120-131.

35. DiNuzzo, M.; Mangia, S.; Maraviglia, B.; Giove, F. Physiological bases of the $\mathrm{K}^{+}$and the glutamate/GABA hypotheses of epilepsy. Epilepsy Res. 2014, 108, 995-1012.

36. Nissou, M.F.; Guttin, A.; Zenga, C.; Berger, F.; Issartel, J.P.; Wion, D. Additional clues for a protective role of vitamin D in neurodegenerative diseases: 1,25-dihydroxyvitamin D3 triggers an anti-inflammatory response in brain pericytes. J. Alzheimer's Dis. 2014, 42, 789-799.

37. Kajta, M.; Makarewicz, D.; Zieminska, E.; Jantas, D.; Domin, H.; Lason, W.; Kutner, A.; Lazarewicz, J.W. Neuroprotection by co-treatment and post-treating with calcitriol following the ischemic and excitotoxic insult in vivo and in vitro. Neurochem. Int. 2009, 55, 265-274.

(C) 2015 by the authors; licensee MDPI, Basel, Switzerland. This article is an open access article distributed under the terms and conditions of the Creative Commons Attribution license (http://creativecommons.org/licenses/by/4.0/). 